Journal of Applied Pharmaceutical Science Vol. 5 (09), pp. 021-025, September, 2015

Available online at http://www.japsonline.com

DOI: 10.7324/JAPS.2015.50904

ISSN 2231-3354 (cc) BY-NC-SA

\title{
Antimicrobial activity and chemical composition of essential oil and hydrosol extract of Nepeta nepetella subsp. amethystina (Poir.) Briq. from Algeria
}

\author{
Chafika Bellahsene ${ }^{1}$, Mourad Bendahou ${ }^{1 *}$, Abdelmounaïm Khadir ${ }^{1,2}$, Fatima Zenati ${ }^{1}$, Fethi Benbelaïd ${ }^{1}$, Nadia Aissaoui ${ }^{1}$, \\ Alain Muselli ${ }^{3}$, Jean Costa ${ }^{3}$ \\ ${ }^{1}$ Laboratory of Applied Microbiology in Food, Biomedical and Environment (LAMAABE), AbouBekr Belkaïd University, PO Box 119, 13000 Tlemcen, \\ Algeria. ${ }^{2}$ Department of Biology, University Oran 1 Ahmed Benbella, Oran, Algeria. ${ }^{3}$ Université de Corse, UMR CNRS 6134, Laboratoire Chimie des \\ Produits Naturels, 20250 Corti, France.
}

\author{
ARTICLE INFO \\ Article history: \\ Received on: 12/06/2015 \\ Revised on: 17/07/2015 \\ Accepted on: 11/08/2015 \\ Available online: 27/09/2015 \\ Key words: Nepeta nepetella \\ subsp. amethystina, essential \\ oil, hydrosol extract, \\ nepetalactones, antimicrobial \\ activity.
}

\begin{abstract}
The essential oil and hydrosol extract of Nepeta nepetella subsp. amethystina, obtained by hydrodistillation and analysed by GC, GC-MS, 1H and 13C NMR, were evaluated for their antimicrobial activity using disks diffusion method and MICs against thirteen pathogenic microorganisms. The chemical analysis of essential oil and hydrosol extract allowed the identification of 34 and 12 constituents representing $96.77 \%$ and $80.07 \%$ of total oil and hydrosol extract, respectively. The two isomers $4 \mathrm{a} \alpha, 7 \alpha, 7 \mathrm{a} \beta$-nepetalactone and $4 \mathrm{a} \alpha, 7 \alpha, 7 \mathrm{a} \alpha$-nepetalactone were found to be the major components in N. amethystina essential oil and hydrosol extract, $\alpha, 7 \alpha$-nepetalactone and $4 \mathrm{a} \beta, 7 \mathrm{a} \alpha, 7 \alpha$ respectively. The two isomers $4 \mathrm{a}$-nepetalactone were found to be the major components in N. $\alpha 7 \mathrm{a}$ amethystina essential oil and hydrosol extract. Candida albicans strains were the most sensitive microorganisms towards $N$. amethystina essential oil and hydrosol extract, which have the largest inhibition zones ( $>30 \mathrm{~mm})$ and the lower MICs values $(<1.25 \%)$. The anti-mold activity, carried out by the diffusion method, showed that $N$. amethystina essential oil has a very interesting activity against Aspergillus flavus and Cladosporium herbarium.
\end{abstract}

\section{INTRODUCTION}

The genus Nepeta which belonged to Lamiaceae family is represented by more than 250 species distributed mainly in Africa, Europe and Asia (Mabberly, 1997). 7\% of total Nepeta species growth wild in the Iberian Peninsula and North Africa, in which only five species exist in Algeria (Quézel and Santa, 1962; Greuter et al., 1986). According to taxonomic revision of Ubera \& Valdes (Castrillón and Jiménez, 1983), N. amethystina is a subspecies of $N$. nepetella. This medicinal plant is found in Saharan Atlas in dry stony places. Locally, N. amehtystina is named Gouzia and it's mostly used as a medicinal plant for its febrifuge, antirheumatic, antispasmodic and diuretic effects. The essential oils of some Nepeta species have been extensively studied, which are mainly characterized by nepetalactone (Dabiri and Sefidkon, 2003; Sefidkon et al., 2006). The compounds 1,8-

\footnotetext{
* Corresponding Author

Mourad Bendahou, Laboratory of Applied Microbiology in Food, Biomedical and Environment (LAMAABE), AbouBekr Belkaïd University, PO Box 119, 13000 Tlemcen, Algeria.

Email: bendahou63@yahoo.fr
}

cineole and D-germacrene were also identified as the main constituent of the essential oils of $N$. ispahanica and $N$. ucrainica (Rustaiyan and Nadji, 1999; Javidnia et al., 2005), respectively. Essential oil obtained from $N$. amethystina subsp. amethystina of Spanish origin showed that $4 \mathrm{a} \alpha, 7 \alpha, 7 \mathrm{a} \alpha$-nepetalactone was the main constituents (41.29\%) followed by $4 \mathrm{a} \alpha, 7 \alpha, 7 \mathrm{a} \beta$ nepetalactone $(29.42 \%)$ and an aldehyde not identified $(5.30 \%)$ (Velasco-Negueruela et al., 1989). To our knowledge there are no reports on the antimicrobial properties of $N$. amethystina. This study aimed the determination of chemical composition and antimicrobial activity of $N$. amethystina essential oil and hydrosol extract.

\section{MATERIALS AND METHODS}

\section{Plant material}

The aerial parts of $N$. amethystina were collected during flowering stage in June 2011 from Aïn-Safra region located in western Algeria. The plant material was identified by Dr. Boumediene Medjahdi according to (Quézel and Santa, 1962). 
A voucher specimen has been deposited in the Herbarium of the Laboratory of Botany, Department of Biology, Tlemcen University, Algeria.

\section{Preparation of essential oil (EO) and hydrosol extract (HY)}

EO from air-dried aerial parts (250g) was obtained by hydrodistillation for $5 \mathrm{~h}$ using a Clevenger type apparatus according to the (European-Pharmacopoeia, 2005). The oil was separated from hydrosol and dried over anhydrous sodium sulfate and stored in sealed vials at $4 \mathrm{C}^{\circ}$. The $500 \mathrm{ml}$ first liters of water hydro-distillation (hydrosol) were extracted three times with 100 $\mathrm{ml}$ of diethyl ether $\left(\mathrm{Et}_{2} \mathrm{O}\right)$ by liquid-liquid extraction. The organic layer was dried over $\mathrm{Na}_{2} \mathrm{SO}_{4}$, evaporated at room temperature until obtained pure extract and stored in sealed vials at low temperature.

\section{EO and $\mathrm{HY}$ analysis procedure}

GC analyses were carried out using a Perkin Elmer Clarus 600 apparatus equipped with a dual flame ionisation detection system and two fused-silica capillary columns (60 m x $0.22 \mathrm{~mm}$ i.d., film thickness $0.25 \mu \mathrm{m}), \quad$ Rtx-1 (polydimethylsiloxane) and Rtx-Wax (polyethyleneglycol). GC conditions used were: programmed heating from $60{ }^{\circ} \mathrm{C}$ to $230{ }^{\circ} \mathrm{C}$ at $2^{\circ} \mathrm{C} / \mathrm{min}$, followed by $35 \mathrm{~min}$ under isothermal conditions. The injector and the detector were maintained at $280{ }^{\circ} \mathrm{C}$. Helium was the carrier gas at $1 \mathrm{ml} / \mathrm{min} ; 0.2 \mu \mathrm{L}$ of EO was injected in the split mode (1:50). EO and HY was analysed with a Perkin Elmer Turbo Mass detector, directly coupled to a Perkin Elmer Autosystem XL equipped with fused-silica capillary columns (60 m x $0.22 \mathrm{~mm}$ i.d., film thickness $0.25 \mu \mathrm{m}$ ), Rtx-1 (polydimethylsiloxane) and RtxWax (polyethyleneglycol). GC-MS (EI) conditions: Ion source temperature: $150^{\circ} \mathrm{C}$; energy ionization: $70 \mathrm{eV}$; electron ionisation mass spectra were acquired oven the mass range 35-350 Da. Split: $1 / 80$. Identification of the components was based i) on the comparison of their GC retention indices (RI) on non-polar and polar columns, determined relative to the retention time of a series of n-alkanes C9-C24 with linear interpolation, with those of authentic compounds or literature data; and ii) on computer matching with commercial mass spectral libraries (Hochmunth, 2001; Köning et al., 2001) and comparison of spectra with those of our personal library "Aromes". Relative amount of individual components were performed on the basis of their GC peak areas on the two capillary Rtx-1 and Rtx-Wax columns, without FID response factor correction.

\section{Isolation of nepetalactones and NMR analysis}

The dichloromethane extract of aerial part of $N$. amethystine was subjected to flash chromatography (silica gel 200-500 $\mu \mathrm{m}$ ), eluting with different solvents of increasing polarity. We obtained several fractions with the highest was subjected to

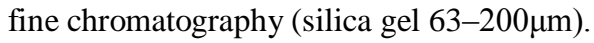

Thus, we recovered 8 fractions. The sixth fraction $(0.02$ g) obtained with petrol ether/dichloromethane (75/25) was analyzed by NMR. The NMR spectra were recorded on a Bruker DPX 300 instrument in deuterated chloroform.

\section{Antimicrobial activity Microbial strains}

$N$. amethystina EO and HY were evaluated against eight bacterial reference strains, which are Escherichia coli (E. coli) ATCC 25922, Pseudomonas aeruginosa (P. aeruginosa) ATCC 27853, Enterococcus faecalis (E. faecalis) ATCC 29212, Klebsiella pneumonia (K. pneumoniae) ATCC 700603, Staphylococcus aureus (S. aureus) ATCC 29213, Bacillus cereus (B. cereus) ATCC 11778, Bacillus subtilis (B. subtilis) ATCC 6633, Listeria monocytogenes (L. monocytogenes) ATCC 19115 and against three different strains of Candida albicans ( $C$. albicans) ATCC 10231, C. albicans ATCC 26790 and C. albicans IPP 444 (Institut Pasteur Paris). The anti-mold activity was tested against two mold strains obtained from National Museum of Natural History of Paris (MNHN), which are Aspergillus flavus (A. flavus) MNHN 994294 and Cladosporium herbarum (C. herbarum) MNHN 3369.

\section{Inoculums preparation}

The inoculums of the bacterial and yeasts strains were prepared from overnight broth cultures. The suspensions were set to 0.5 McFarland or an optical density from 0.08 to 0.13 at $625 \mathrm{~nm}$ wavelength, which corresponds to $10^{8} \mathrm{cfu} / \mathrm{mL}$ (CLSI, 2006).

\section{Disc diffusion assay}

EO and HY of $N$. amethystina were tested for their antimicrobial activity using the diffusion technique on solid media (Benbelaïd et al., 2014). Discs of sterile Whatman paper $(\varnothing 6 \mathrm{~mm})$ were impregnated with $4 \mu \mathrm{l}$ of extracts EO and HY, and then placed on dish plates of Mueller-Hinton Agar (Pronadisa ${ }^{\mathrm{TM}}$, Spain), which had been inoculated with an inoculum of $10^{8}$ $\mathrm{cfu} / \mathrm{mL}$. The plates were then incubated for $24 \mathrm{~h}$ at $37^{\circ} \mathrm{C}$ for bacteria and $30^{\circ} \mathrm{C}$ for yeast. The results were recorded by measuring the growth inhibition zones surrounding the discs. All tests were performed in triplicate.

\section{Determination of minimum inhibitory concentration (MIC)}

The MIC was established by the broth microdilution method according to the Clinical and Laboratory Standards Institute (CLSI, 2006).

DMSO was used to dissolve the EO and HY. A serial doubling dilution of the oil was prepared in a 96 well microliter plate over the range of $40.00-0.08 \mathrm{mg} / \mathrm{mL}$ inoculated in MuellerHinton broth. The MIC was defined as the lowest concentration of EO and HY that inhibiting visible growth. All tests were performed in triplicate.

\section{Anti-mold activity (Agar dilution method)}

The anti-mold activity of $N$. amethystina EO and HY was determinate using the agar dilution method (Hili et al., 1997). Briefly, $6 \mathrm{~mm}$ agar discs of each mold cultures were deposited in the centre of Petri plate $(90 \mathrm{~mm})$ containing $20 \mathrm{ml}$ of Potato Dextrose Agar (Merck, France), with various concentrations of EO 
and HY. The testing dishes were incubated at $25^{\circ} \mathrm{C}$ for 7 days, the anti-mold indices were calculated as follows:

$$
\mathrm{AI}(\%)=[(\mathrm{DC}-\mathrm{DE}) / \mathrm{DC}] \times 100
$$

$\mathrm{DE}$ : the diameter of growth zone in the experimental dish $(\mathrm{mm})$; DC: the diameter of growth zone in the control dish (mm)

\section{Statistical analysis}

Statistical analyses were performed withthe GraphPad Prism 5 software. Statistical comparisons were made with twoway ANOVA followed by Bonferroni's test. The level of significance was set at $P<0.05$.

\section{RESULTS AND DISCUSSION}

The plant extractions provide yellow pale oil by hydrodistillation which yield $0.60 \%$, whereas hydrosol extract gave dark yellow oil yielded $0.39 \%$. The chemical composition of EO and HY from N. amethystina was listed in table 1.

A total of thirty-four compounds were identified in $N$. amethystina EO and HY obtained from the aerial parts of $N$. amethystina, representing 96.77 and $80.07 \%$ respectively.
All components were identified by comparison of their EI-MS and GC-retention indices and mass spectral with those of the "Arômes" library. Oxygenated monoterpenes compounds were the major groups in EO and $\mathrm{HY}$, while hydrocarbon monoterpenes and hydrocarbon sesquiterpenes were absent in HY. The major components were found to be $4 \mathrm{a} \alpha, 7 \alpha, 7 \mathrm{a} \beta$-nepetalactone $(72.40 \%, 49.21 \%)$ and $4 \mathrm{a} \alpha, 7 \alpha, 7 \mathrm{a} \alpha$-nepetalactone $(16.25 \%$, $4.71 \%$ ) of EO and HY respectively. This result contrasts with that obtained by Velasco-Negueruela et al. (1989). These authors have found cis-trans- nepetalactone $(41.90 \%)$ as the main compound followed by the isomer trans-cis- nepetalactone (39.40\%) of EO from $N$. amethystina of Spanish origin. The isomers nepetalactone finding in our work looks like the species of $N$. argolic, $N$. nepetella subsp. aragonensis and N. nuda (De Pooter et al., 1987; Velasco-Negueruela et al., 1998; Tzakou et al., 2000). We note also the presence of myrtenal, carvacrol, $\beta$-farnesene, $\beta$-ionone, $\alpha$ muurolene and $\gamma$-cadinene which were reported for the first time in $N$. amethystina from Algeria. The antibacterial and anti-fungal activities of $N$. amethystina $\mathrm{EO}$ and $\mathrm{HY}$ were assessed by disc diffusion and MIC methods.

Table 1: Chemical composition of essential oil (EO) and hydrosol extract (HY) of Algerian N. amethystina.

\begin{tabular}{|c|c|c|c|c|c|c|}
\hline Sl. No. & Components & $\mathbf{R I}^{\mathbf{a}}$ & $\mathbf{R I}^{\mathbf{b}}$ & EO & HY & Identification \\
\hline 1 & (z)-Hex-2-en-1-ol & 826 & 1405 & $\mathrm{Tr}$ & - & RI, MS \\
\hline 2 & $\alpha$-Pinene & 931 & 1022 & 0.20 & - & RI, MS \\
\hline 3 & Camphene & 945 & 1066 & $\operatorname{Tr}$ & - & RI, MS \\
\hline 4 & Octan-3-one & 959 & 1337 & 0.10 & - & RI, MS \\
\hline 5 & Sabinene & 966 & 1120 & $\operatorname{Tr}$ & - & RI, MS \\
\hline 6 & $\beta$-Pinene & 971 & 1110 & 0.41 & - & RI, MS \\
\hline 7 & p-Cymene & 1014 & 1268 & 0.23 & - & RI, MS \\
\hline 8 & 1,8-Cineole & 1022 & 1209 & 0.45 & 2.25 & RI, MS \\
\hline 9 & (Z)- $\beta$-Ocimene & 1024 & 1230 & 0.10 & - & RI, MS \\
\hline 10 & $\gamma$-Terpinene & 1050 & 1243 & $\operatorname{Tr}$ & - & RI, MS \\
\hline 11 & Linalool & 1086 & 1544 & 0.12 & 1.70 & RI, MS \\
\hline 12 & trans-p-Menth-2-en-1-ol & 1123 & 1625 & 0.10 & 1.40 & RI, MS \\
\hline 13 & Camphor & 1124 & 1517 & 0.21 & 1.31 & RI, MS \\
\hline 14 & Terpinene 4-ol & 1166 & 1600 & 0.32 & 6.11 & RI, MS \\
\hline 15 & $\alpha$-Terpineol & 1181 & 1700 & 0.41 & 2.80 & RI, MS \\
\hline 16 & Myrtenal & 1182 & 1498 & 0.21 & 0.11 & RI, MS \\
\hline 17 & trans-Piperitol & 1189 & 1738 & 0.40 & 1.50 & RI, MS \\
\hline 18 & Linalyl acetate & 1247 & 1565 & $\operatorname{Tr}$ & - & RI, MS \\
\hline 19 & Thymol & 1277 & 2189 & 2.30 & 1.51 & RI, MS \\
\hline 20 & Bornyl acetate & 1280 & 1575 & 0.50 & - & RI, MS \\
\hline 21 & Carvacrol & 1283 & 2219 & 0.35 & 0.23 & RI, MS \\
\hline 22 & 4a $\alpha, 7 \alpha, 7 \mathbf{a} \alpha$-nepetalactone & 1333 & 1953 & 16.25 & 4.71 & RI, MS, ${ }^{1} \mathrm{H}$ and ${ }^{13} \mathrm{C}$ NMR \\
\hline 23 & $4 a \alpha, 7 \alpha, 7 a \beta$-nepetalactone & 1373 & 2019 & 72.40 & 49.21 & $\mathrm{RI}, \mathrm{MS},{ }^{1} \mathrm{H}$ and ${ }^{13} \mathrm{C}$ NMR \\
\hline 24 & (E)- $\beta$-Caryophyllene & 1420 & 1591 & 0,60 & 0.31 & RI, MS \\
\hline 25 & $\alpha$-Humulene & 1453 & 1665 & 0.10 & - & RI, MS \\
\hline 26 & (E)- $\beta$-Farnesene & 1452 & 1665 & 0.21 & - & RI, MS \\
\hline 27 & $\beta$-Ionone & 1462 & 1923 & $\operatorname{Tr}$ & - & RI, MS \\
\hline 28 & $\alpha$-Muurolene & 1494 & 1716 & 0.10 & - & RI, MS \\
\hline 29 & $\gamma$-Cadinene & 1509 & 1752 & 0.20 & - & RI, MS \\
\hline 30 & Elemol & 1536 & 2076 & $\operatorname{Tr}$ & 2.21 & RI, MS \\
\hline 31 & Spathulenol & 1560 & 2119 & $\operatorname{Tr}$ & 1.20 & RI, MS \\
\hline 32 & Caryophyllene oxide & 1572 & 1980 & 0.40 & 1.31 & RI, MS \\
\hline 33 & $\tau$-Cadinol & 1631 & 2163 & 0.10 & 1.50 & RI, MS \\
\hline 34 & $\alpha$-Cadinol & 1643 & 2227 & $\operatorname{Tr}$ & 0.70 & RI, MS \\
\hline 35 & Total & & & 96.77 & 80.07 & \\
\hline 36 & Yields \% (w/w) & & & 0.60 & 0.39 & \\
\hline 37 & Hydrocarbon monoterpenes & & & 0,84 & - & \\
\hline 38 & Oxygenated monoterpenes & & & 94,72 & 73.15 & \\
\hline 39 & Hydrocarbon sesquiterpenes & & & 0,61 & - & \\
\hline 40 & Oxygenated sesquiterpenes & & & 0,50 & 6,92 & \\
\hline
\end{tabular}

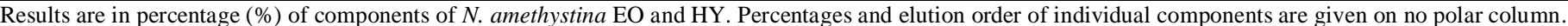

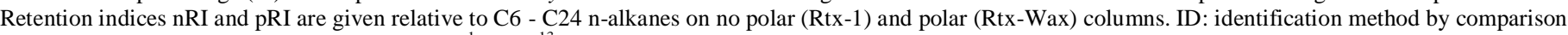
of (RI) retention indices and (MS) mass spectra. ${ }^{1} \mathrm{H}$ and ${ }^{13} \mathrm{C}$ NMR: proton and carbon nuclear magnetic resonance. 
Table 2: Antibacterial and anti-yeast activities of N. amethystina essential oil (EO) and hydrosol extract (HY).

\begin{tabular}{|c|c|c|c|c|}
\hline \multirow[b]{2}{*}{ The microbial stumps } & \multicolumn{2}{|c|}{ IZ } & \multicolumn{2}{|c|}{ MIC } \\
\hline & EO & HY & EO & HY \\
\hline$\overline{E . \text { coli }}$ & $11 \pm 1$ & $9 \pm 1$ & $20 \pm 0.000^{g}$ & $40 \pm 0.000^{\mathrm{g}}$ \\
\hline P. aeruginosa & $8 \pm 0$ & $7 \pm 1$ & $40 \pm 0.000$ & $40 \pm 0.000$ \\
\hline K. pneumoniae & $8 \pm 1$ & $7 \pm 1$ & $40 \pm 0.000$ & $40 \pm 0.000$ \\
\hline E. faecalis & $14 \pm 1$ & $12 \pm 1$ & $10 \pm 0.000^{\mathrm{h}}$ & $20 \pm 0.000^{\mathrm{h}}$ \\
\hline S. aureus & $22 \pm 1^{\mathrm{a}}$ & $18 \pm 1^{\mathrm{a}}$ & $1.25 \pm 0.000$ & $1.25 \pm 0.000$ \\
\hline B. cereus & $24 \pm 2^{\mathrm{b}}$ & $18 \pm 1^{\mathrm{b}}$ & $1.25 \pm 0.000^{\mathrm{i}}$ & $2.5 \pm 0.000^{\mathrm{i}}$ \\
\hline B. subtilis & $20 \pm 1^{c}$ & $16 \pm 1^{\mathrm{c}}$ & $1.25 \pm 0.000^{\mathrm{j}}$ & $2.5 \pm 0.000^{\mathrm{j}}$ \\
\hline L. monocytogenes & $12 \pm 1$ & $10 \pm 1$ & $10 \pm 0.000^{\mathrm{k}}$ & $20 \pm 0.000^{\mathrm{k}}$ \\
\hline C. albicans IPP 444 & $37 \pm 2^{\mathrm{d}}$ & $32 \pm 1^{\mathrm{d}}$ & $0.520 \pm 0.180^{1}$ & $1.25 \pm 0.000^{1}$ \\
\hline C. albicans ATTC 10231 & $45 \pm 2^{\mathrm{e}}$ & $37 \pm 2^{\mathrm{e}}$ & $0.416 \pm 0.180$ & $0.520 \pm 0.180$ \\
\hline C. albicans ATTC 26790 & $40 \pm 1^{\mathrm{f}}$ & $35 \pm 2^{\mathrm{f}}$ & $0.625 \pm 0.000^{\mathrm{m}}$ & $1.25 \pm 0.000^{\mathrm{m}}$ \\
\hline
\end{tabular}

All results shown in this Table are: Mean \pm Standard Deviation (SD) of three repeats. The data were analysed by two-way ANOVA followed by Bonferroni's test. Values in the same row followed by the same letter are significantly different $(\mathrm{P}<0.001)$. IZ: inhibition zones in millimetre. MIC: minimal inhibitory concentration in $\mathrm{mg} / \mathrm{ml}$.

Table 3: Results of inhibiting effect of $N$. amethystina essential oil (EO) and hydrosol extract (HY) on mycelia growth.

\begin{tabular}{|c|c|c|c|}
\hline Mold strain & Volume added & (AI ) of EO\% & (AI) of HY \% \\
\hline \multirow{3}{*}{ A. flavus MNHN 994294} & 10 & 4.75 & 12.5 \\
\hline & 50 & 40.47 & 37.5 \\
\hline & 100 & 100 & 66.66 \\
\hline \multirow{3}{*}{ C. Herbarum MNHN 3369} & 10 & 27.71 & 2.4 \\
\hline & 50 & 68.67 & 45.78 \\
\hline & 100 & 79.51 & 61.44 \\
\hline
\end{tabular}

AI: anti-mould indice.

The EO and HY showed strong antimicrobial activity against microbial species (Table 2), especially against yeast. In most, the Gram positive bacteria are more sensitive to EO and HY than Gram negative ones. B. cereus was the most sensitive bacterial species, with inhibition zones larger than $18 \mathrm{~mm}$. However, P. aeruginosa and K. pneumoniae appears resistant to $N$. amethystina EO and HY. While $C$. Albicans was very sensitive to both EO and HY with inhibition zones larger than $30 \mathrm{~mm}$. The MICs of the studied oil and HY ranged between 0.416 and 40 $\mathrm{mg} / \mathrm{mL}$ (Table 02). The lowest MICs were observed against $C$. albicans ATCC10231 with an MIC of $0.416 \mathrm{mg} / \mathrm{ml}$ for oil and $0.520 \mathrm{mg} / \mathrm{ml}$ for HY. Against molds, EO and HY of N. amethystina have showed a good activity (Table 03). The EO exhibited more activity against A. flavus than $C$. herbarum. The antimicrobial activity of $N$. amethystina EO and HY may be related to their major monoterpenoid component i.e. nepetalactone, since it's known by its antimicrobial potency (Farag et al., 1989). The antimicrobial activity of EOs is also due to minor components might contribute into antimicrobial activity (Kobaisy et al., 2005). Indeed, the minor constituents like 1,8 cineol, terpinene 4-ol, $\alpha$ terpineol, and thymol may involve in the antimicrobial activity of N. amethystina EO and HY (Tao et al., 2014; Zhou et al., 2014). Many previous studies have shown the relationship between the antimicrobial activity of EOs and their chemical composition (Deans and Svoboda, 1989; Farag et al., 1989) and the role of synergy in the antimicrobial activity of EOs (Benbelaïd et al., 2014). We also find that the EO is more active on microorganisms than the HY. This result is contrary to that of the literature that reports that the hydrosol rich in hydrophilic oxygen molecules exerts more activity than the oil rich in lipophilic compounds (Rose, 1999; Rao et al., 2002). In this study, we have evaluated the antimicrobial activities of the EO and HY of $N$. amethystina harvested in Algeria. N. amethystina EO and HY were effective in growth inhibition of all tested strains. According to the extracts, EO was more active than the HY, but according to strains, $C$. albicans and B. cereus were shown to be more sensitive to both extracts. As a consequence this oil can be used as possible alternatives or complementary therapeutic agent against candidiasis.

Also, the oil can be useful for developing alternative compounds to preserved food contaminations caused by $B$. cereus and inhibits mold growths.

\section{CONCLUSION}

In conclusion, we show once again the interest of natural products in the control of microbial growth and especially the use of oil and its by-product of steam distillation hydrolat as antimicrobial agent's preservatives in agro- foods or as antiseptic agents in therapies.

\section{Conflict of interest statement}

We declare that we have no conflict of interest.

\section{ACKNOWLEDGEMENTS}

Authors would thank Dr. Boumediene Medjahdi, Forestry and Agronomy Department, Aboubekr Belkaïd University of Tlemcen, for the $N$. amethystina identification.

\section{REFERENCES}

Benbelaïd F, Khadir A, Abdoune MA, Bendahou M, Muselli A, Costa J. Antimicrobial activity of some essential oils against oral multidrug-resistant Enterococcus faecalis in both planktonic and biofilm state. Asian Pac J Trop Biomed, 2014; 4: 463-472. 
Castrillón BV, Jiménez JLU. Revisión del género Nepeta (Labiatae) en la Península Ibérica e islas Baleares. Lagascalia, 1983; 12: $3-80$.

CLSI. 2006. Methods for Dilution Antimicrobial Susceptibility Tests for Bacteria That Grow Aerobically. Wayne, United State: Clinical and Laboratory Standards Institute.

Dabiri M, Sefidkon F. Chemical composition of the essential oil of Nepeta racemosa Lam. from Iran. Flavour Fragr J, 2003; 18: 157158.

De Pooter HL, Nicolai B, De Buyck LF, Goetghebeur P , Schamp NM. The essential oil of Nepeta nuda-Identification of a new nepetalactone diastereoisomer. Phytochemistry, 1987; 26: 2311-2314.

Deans SG , Svoboda KP. Antimicrobial activity of summer savory (Satureja hortensis L.) essential oil and its constituents. J Hortic Sci, 1989; 64: 205-210.

European-Pharmacopoeia. 2005. Sainte Ruffine: Maissoneuve.

Farag RS, Daw ZY, Hewedi FM , El-Baroty GSA. Antimicrobial activity of some Egyptian spice essential oils. Journal of food protection, 1989; 52: 665-667.

Greuter W, Burdet HM , Long G. 1986. Conservatoire et Jardin botaniques de la Ville de Genève. Geneva, Switzerland.

Hili P, Evans CS , Veness RG. Antimicrobial action of essential oils-the effect of dimethylsulphoxide on the activity of cinnamon oil. Lett Appl Microbiol, 1997; 24: 269-275.

Hochmunth DH (2001). It means of a software of a data base called MassFinder Germany, Scientific Consulting.

Javidnia K, Miri R, Mehregan I, Sadeghpour H. Volatile constituents of the essential oil of Nepeta ucrainica L. ssp. kopetdaghensis from Iran. Flavour Fragr J, 2005; 20: 219-221.

Kobaisy M, Tellez MR, Dayan FE, Mamonov LK, Mukanova GS, Sitpaeva GT , Gemejieva NG. Composition and phytotoxic activity of Nepeta pannonica L. essential oil. J Essent Oil Res, 2005; 17: 704-707.

Köning WA, Hochmuth DH , Joulain D. 2001. Terpenoids and related constituents of essential oils. Hambourg, Germany: University of Hambourg.

Mabberly DJ. 1997. The plant book. Cambridge, United Kingdom: Cambridge University Press.

Quézel P, Santa S. 1962. Nouvelle flore d'Algérie et des régions désertiques méridionales. Paris, France: Editions du Centre National de la Recherche Scientifique.
Rao BR, Kaul P, Syamasundar K, Ramesh S. Water soluble fractions of rose-scented geranium (Pelargonium species) essential oil. Bioresour Technol, 2002; 84: 243-246.

Rose J. 1999. Essential oils and hydrosols: Frog edition.

Rustaiyan A , Nadji K. Composition of the essential oils of Nepeta ispahanica Boiss. and Nepeta binaludensis Jamzad from Iran. Flavour Fragr J, 1999; 14: 35-37.

Sefidkon F, Jamzad Z , Mirza M. Chemical composition of the essential oil of five Iranian Nepeta species (N. crispa, N. mahanensis, $N$. ispahanica, N. eremophila and N. rivularis). Flavour Fragr J, 2006; 21: 764-767.

Tao N, Jia L, Zhou H. Anti-fungal activity of Citrus reticulata Blanco essential oil against Penicillium italicum and Penicillium digitatum. Food Chem, 2014; 153: 265-271.

Tzakou O, Harvala C, Galati EM , Sanogo R. Essential oil composition of Nepeta argolica Bory et Chaub. subsp. argolica. Flavour Fragr J, 2000; 15: 115-118.

Velasco-Negueruela A, M. RM, Benito PB , Perez-Alonso MJ. Composition de los aceites esentiales de Nepeta nepetella subsp. aragonensis, Nepeta coerulea subsp. coerulea y Nepeta cataria. Giardino Botanico Italiano, 1998; 122: 295-302.

Velasco-Negueruela A, PEREZ-ALONSO M , Buades Rodriguez A. Continuación del estudio químico de los aceites esenciales de nepetas ibéricas-Nepeta nepetella L. y N. amethystina Poiret. An Jard Bot Madr, 1989; 47: 395-400.

Zhou H, Tao N , Jia L. Antifungal activity of citral, octanal and $\alpha$-terpineol against Geotrichum citri-aurantii. Food Control, 2014; 37: $277-283$.

\section{How to cite this article:}

Chafika Bellahsene, Mourad Bendahou, Abdelmounaïm Khadir, Fatima Zenati, Fethi Benbelaid, Nadia Aissaoui, Alain Muselli, Jean Costa. Antimicrobial activity and chemical composition of essential oil and hydrosol extract of Nepeta nepetella subsp. amethystina (Poir.) Briq. from Algeria. J App Pharm Sci, 2015; 5 (09): 021-025. 